\title{
Social x Digital: uma análise do uso das TIC no contexto escolar
}

\section{Social $x$ Digital: an analysis of the use of ICT in the school context}

\author{
Wylnara Braga ${ }^{* * *}$, Bento Silva** \\ *Instituto Federal de Educação, Ciência e Tecnologia do Amazonas, **Universidade do Minho
}

\begin{abstract}
Resumo
Este trabalho, decorrente de uma dissertação de mestrado em curso, busca analisar de que forma a escola pode contribuir para a inclusão digital frente às desigualdades sociais e quais interferências que a realidade social dos estudantes do Instituto Federal do Amazonas - Campus Manaus Zona Leste (IFAM-CMZL) possuem no acesso às TIC. Para isso, foi realizado um estudo survey de tipo descritivo e exploratório, através da aplicação de um questionário eletrônico sobre aspectos socioeconômicos e tecnológicos aos estudantes do IFAM-CMZL localizado na cidade de Manaus-Amazonas no Brasil.

Palavras- Chaves: Inclusão Social, Inclusão Digital, Tecnologias da Informação e Comunicação.
\end{abstract}

\begin{abstract}
This work, based on an ongoing Master's dissertation, seeks to analyze how the school can contribute to digital inclusion in the face of social inequalities and what interferences the social reality of Federal Institute of Amazonas - Campus Manaus Zona Leste (IFAM-CMZL) students has in accessing ICT. For this, a descriptive and exploratory study was carried out, through the application of an electronic questionnaire on socioeconomic aspects and technological to the students of IFAM-CMZL located in the city of Manaus- Amazonas in Brazil.

Keywords: Social Inclusion, Digital Inclusion, Information and Communication Technologies.
\end{abstract}

\section{Introdução}

Partimos do pressuposto que inclusão é qualquer atitude, política ou tendência, seja do ponto de vista econômico, político, educativo, ou outros, que integra. Que a inclusão social integra o conjunto de meios e ações que combatem a exclusão aos benefícios da vida em sociedade, provocada pelas diferenças de classe social, educação, idade, deficiência, gênero, preconceito social ou preconceitos raciais. E que a inclusão digital é a democratização do acesso às Tecnologias da Informação e Comunicação (TIC) e seus mecanismos, de modo a inserir todos os sujeitos em sociedade e educá-los para uso dessas tecnologias. Assim, este artigo traz a debate a seguinte questão: de que forma a escola pode contribuir para a inclusão digital frente às desigualdades sociais e quais interferências que realidade social dos estudantes do IFAM-CMZL possuem no acesso às TIC?

Tedesco (2002) ressalta que um dos fenômenos mais importantes nas transformações sociais atuais é o aumento significativo da desigualdade social. Estando a inclusão diretamente ligada aos processos de exclusão social há que compreender os tipos de exclusão para podermos pensar em políticas inclusivas.

Em detrimento do avanço tecnológico, a internet tem sido a melhor ferramenta de interação com o mundo, de tal modo que a Organização das Nações Unidas declarou recentemente, através da resolução A/HRC/32/L.20 aprovada em $1^{\circ}$ de julho de 2016, que o acesso à Internet é um direito humano, a acrescentar à Carta das Nações Unidas, devendo ser garantido o direito à liberdade de opinião e expressão, reforçando, ainda, que ao negar-se esse acesso comete-se um crime de violação dos direitos humanos (ONU, 2016).

Segundo os dados do Internet World Stats (IWS, 2016) referente ao ano de 2016, apenas 50,1\% da população mundial tem acesso à internet. Na América da Sul há um total de $66,7 \%$ de usuários. Não obstante estas limitações, há que reconhecer que tem havidos avanços significativos na inclusão digital. Em 2003, apenas $12,46 \%$ dos brasileiros tinham computador em suas residências e pouco mais de $8,31 \%$ encontravam-se conectados à Internet. (FGV, 2003). Em 2010 esse índice cresceu no Brasil. Passou para $41,11 \%$ a população com microcomputador em domicilio e para $33,2 \%$ as que possuem microcomputador com internet. Os avanços foram sendo ainda mais significativos, e a ultima pesquisa do IWS (2016) demonstrou que o Brasil está com $67,5 \%$ da população fazendo uso de internet. Contudo, apesar da taxa de crescimento significativa, desde a entrada no século XXI, registra-se que quase metade da população está ainda excluída digitalmente.

Filho (2003) elencou os três pilares fundamentais para que a inclusão digital aconteça: TIC, renda e educação. Para isso, o tripé deve estar conectado entre si. Para melhor compreensão, resume-se: sem renda não é possível comprar computador ou pagar um plano de internet. Menos ainda, podemos dizer que basta a existência de internet ou computador para ser incluído digitalmente, uma vez que sem o aprendizado do uso desses recursos, também não é possível estar "conectado". Pode haver, assim, uma inlusão excludente: inclusão no acesso (aquisição da tecnologia) mas uma exlusão no uso, se não se tiver competências para usar as tecnologias nas suas plenitudes.

A exclusão digital reflete-se na sociedade trazendo consequências culturais, sociais e econômicas, haja 
visto que a distribuição desigual da tecnologia impossibilita o acesso aos bens e serviços, inclusive a própria inserção social.

Um dos principais locais que propicia essa inclusão é a escola, visto que é um espaço voltado para os avanços sociais, além de ser composto por inúmeras diferenças, sejam elas sociais, religiosas, políticas, regionais, linguística, gênero, cultural, faixa etária, entre outros, e também por sujeitos com características únicas frequentando um mesmo espaço. O desafio é tornar essas tecnologias acessíveis a todos os cidadãos de forma a incluí-los socialmente e digitalmente. Nesta linha de pensamento, Sarmento (2002) questiona: Que pode a escola contra a exclusão social? Sendo a exclusão social fruto das desigualdades sociais presentes na sociedade capitalista, a escola não pode modificar essa realidade por completo. No entanto, ainda que seja de forma minima, entendemos que a escola pode ser um local de transformação social e institucional. A escola é um agente transformador e por isso, a educação tem esse viés de garantia e de luta pelos direitos sociais.

Silva (2011) discorre que a sociedade, denominada por ele de Sociedade da Informação e Conhecimento (SIC), é repleta de cultura tecnológica com mudanças líquidas (Bauman, 2001) baseadas no individualismo e, antagonicamente, num mundo de rede (Castells, 2002). Portanto, as mudanças estão presentes no modo de agir, comunicar, pensar e aprender das pessoas.

E é diante desta sociedade, "atual e conectada”, que o papel da escola é posto em debate. É possível, pois, afirmar que esse papel tem sofrido profundas transformações e que as novas tecnologias fazem parte destes novos olhares diante da educação. A educação tradicional tem sido colocada em questionamento, uma vez que não acompanha as mudanças sociais.

A Organização das Nações Unidas para a Educação, a Ciência e a Cultura relata que as TIC podem contribuir com o acesso universal da educação, a equidade na educação, a qualidade de ensino e aprendizagem, o desenvolvimento profissional de professores, bem como melhorar a gestão, a governança e a administração educacional ao fornecer a mistura certa e organizada de políticas, tecnologias e capacidades (UNESCO, 2010).

As ações cotidianas no ambiente pedagógico da escola podem ir desde o uso do computador ao uso dos celulares e aplicativos móveis em sala de aula. Pois, além da construção da cidadania e da participação social, essas práticas contribuem para inclusão social. Uma vez que a difusão do conhecimento proporciona igualdade, dignidade e novas oportunidades.

\section{Método}

A metodologia utilizada foi de tipo descritivo e exploratório, através de um levantamento bibliográfico e documental sobre os temas: TIC, inclusão e exclusão social e digital, internet, dentre outros. Foi realizado um estudo survey com aplicação de questionário eletrônico aos estudantes do ensino médio integrado do IFAMCMZL

Segundo Freitas, Oliveira, Saccol e Moscarola (2000), o método de pesquisa survey é quantitativo e sua escolha deve estar associada aos objetivos da pesquisa. Para os autores, "cada desenho de pesquisa ou investigação pode fazer uso de diferentes métodos de forma combinada, o que se denomina de multimétodo" (idem, p.105).

A pesquisa survey, segundo Fink e Kosecoff (1998) e Forza (2002), é um método de coleta de informações diretamente com as pessoas a respeito de suas ideias, sentimentos, saúde, planos, crenças e de fundo social, educacional e financeiro ou sobre a unidade, empresa ou organização que atua. Uma survey pode ser feita através de um questionário onde se completam os dados com ou sem assistência. Esse questionário pode ser enviado pelo correio ou por e-mail. A survey pode ainda ser feita através de entrevistas pessoais ou por telefone. Forza (2002) afirma que a survey determina a informação sobre grandes populações com um nível alto de exatidão. A coleta de informações é feita através de questionários, aplicados no público alvo escolhido para realização da pesquisa.

\section{Objetivos}

$\mathrm{O}$ artigo intitulado "Social x Digital: uma análise do uso das TIC no contexto escolar" tem por objetivo geral analisar de que forma a escola pode contribuir para a inclusão digital frente as desigualdades sociais.

Objetivos específicos: 1) Identificar os conceitos de inclusão social e digital; 2) Verificar de que forma a inclusão social se apresenta na vida dos estudantes do IFAM-CMZL; e 3) Demonstrar de que maneira a inclusão digital pode ser usada para se materializar no ambiente escolar.

\section{Lócus da Pesquisa}

O Instituto Federal de Educação, Ciência e Tecnologia do Amazonas (IFAM) oferece educação profissional aos seus estudantes em diversos níveis e modalidades. Oferta o ensino médio integrado, subsequente, proeja, graduação e pós-graduação. Nas modalidades de ensino à distância e presencial. Atualmente, o IFAM está estabelecido em 20 municípios do Amazonas e em três polos de Educação a Distância em Roraima.

Para esta pesquisa elegeu-se o Campus Manaus Zona Leste (CMZL) localizado na zona leste de Manaus. Por que além de ser o local de trabalho da investigadora (mestranda), logo, facilitaria à recolha de dados, o campus teve sua origem como escola-fazenda e traz, arraigado em sua identidade agrícola, cursos voltados para o primeiro setor

Segundo IBGE (2016), Manaus conta com mais de 2 milhões de habitantes e a zona leste compõe maior parte dessa população. O CMZL localiza-se em uma aérea afastada do centro da cidade, próxima de comunidades ainda rurais. Está rodeado de invasões (termo regional utilizado para denominar as favelas) e 11 bairros predominantemente compostos por família de baixa renda. Por isso, acredita-se que o estudo ficará ainda mais enriquecido, pois o contexto rural e empobrecido é marcado pelas desigualdades, possibilitando relacionarmos "social x digital". 


\section{Instrumentos e Amostra}

Foi utilizado o questionário socioeconómico (eletrônico) institucional já aplicado em março de 2016 aos estudantes do IFAM-CMZL, cuja finalidade é selecionar estudantes em situação de vulnerabilidade social para usufruto dos benefícios estudantis da Política de Assistência Estudantil do IFAM- CMZL.

Semestralmente, todos os estudantes do Campus são convidados a participar do processo de seleção dos Programas Socioassistenciais da Política de Assistência Estudantil e inscrevem-se, em consonância com o edital, conforme suas necessidades.

O questionário socioeconômico é um dos instrumentos de análise utilizado pelo Serviço Social do IFAM-CMZL para avaliar a vulnerabilidade social do estudante. O preenchimento é feito de forma eletrônica e sua aplicação, pela internet. No primeiro semestre de 2016, 643 estudantes preencheram o questionário, de um total de 1.100 matriculados na modalidade de ensino presencial (58,5\% dos estudantes).

Este questionário contém perguntas abertas e fechadas a respeito do perfil socioeconómico, situação de moradia, identificação desses estudantes, inclusão digital, entre outras, por isso, consideramos ser um bom instrumento de análise desta investigação.

Como critérios de inclusão/exclusão do universo da pesquisa, utilizamos: 1) Ser estudante matriculado no IFAM-CMZL; 2) Ter participado do processo de seleção da Assistência Estudantil 2016 no primeiro semestre.

\section{Resultados e Discussão}

Tosoni, Luchetta e Dabul (2011) apontam que, de acordo com os estudos do Instituto de Teleinformação da Columbia Business School, para cada $10 \%$ de aumento na cobertura de banda larga em um país há uma contribuição de 0,18 pontos percentuais ao PIB. Esses estudos apontam também a relação direta entre o acesso à informação e a empregabilidade. No Chile, por exemplo, cerca de 100.000 empregos foram gerados sob o impacto da Internet.

No Brasil, uma pesquisa realizada sobre o acesso à internet e à televisão e posse de telefone móvel celular para uso pessoal em 2013 pelo Instituto Brasileiro de Geografia e Estatística (IBGE, 2015) demonstrou diversos dados importantíssimos sobre o acesso à internet da população brasileira por domicílio. Após realizarem uma ampliação da investigação da utilização da Internet por meio de diversos equipamentos (microcomputador, telefone móvel celular, tablet e outros) estimaram que $49,4 \%$ da população (pessoas de 10 anos ou mais de idade) utilizaram a Internet, pelo menos uma vez no período de referência (últimos 90 dias que antecederam ao dia da entrevista).

Referente a região, o IBGE informou que em 2013, as Regiões Sudeste $(57,0 \%)$, Sul $(53,5 \%)$ e Centro-Oeste $(54,3 \%)$ permaneceram registrando os maiores percentuais de utilização da Internet, considerando-se todos os equipamentos (IBGE, 2015). A Região Norte apresentou o maior acréscimo $(8,7 \%)$ de pessoas de 10 anos ou mais de idade que utilizaram a Internet quando se incluiu o acesso também por meio de outros equipamentos e também apresentou o maior percentual de domicílios que utilizavam o telefone móvel celular para acesso à Internet $(75,4 \%)$.

Informou que no Amazonas (39,6\%), o acesso feito exclusivamente pelo telefone móvel celular ou tablet superou o do microcomputador.

Em seguida, o estudo traz os percentuais de acordo com o tipo de conexão utilizada. Dos 31,2 milhões de domicílios com utilização de Internet em 2013, a maioria $(97,7 \%)$ possui a conexão em banda larga. Sendo estas, $77,1 \%$ banda larga fixa e $43,5 \%$ banda larga móvel. No estado do Amazonas a rede móvel era superior a $80 \%$.

Caraterizando o acesso a Internet por sexos, a pesquisa demonstrou que em 2013, no conjunto do País, não havia diferença significativa entre os percentuais de homens $(49,3 \%)$ e de mulheres $(49,5 \%)$ que utilizavam a Internet. Contudo, nas Regiões Norte, Nordeste e Centro-Oeste, as proporções de mulheres eram maiores $(40,5 \%, 38,0 \%$ e $54,7 \%$, respectivamente) que as observadas entre os homens $(36,7 \%, 36,3 \%$ e $53,9 \%$, na mesma ordem).

$\mathrm{Na}$ análise por distribuição etária, percebeu-se que os grupos mais jovens registravam os maiores percentuais de utilização da Internet. O grupo formado por pessoas de 15 a 17 anos de idade alcançou a maior proporção, $75,7 \%$, sendo $49,4 \%$ a média nacional em 2013. Em todos os grupos compreendidos na faixa de 10 a 39 anos de idade, o uso da Internet ultrapassava 50\%. Os percentuais decresciam com o aumento da idade, sendo que a menor proporção foi observada entre as pessoas de 60 anos ou mais de idade $(12,6 \%)$.

Além disso, os dados mostraram que a utilização da Internet tem uma relação direta com a escolaridade. Para as pessoas com até 7 anos de estudo, o percentual era inferior ao total nacional $(49,4 \%)$, enquanto para aquelas com 8 anos ou mais de estudo a proporção era maior. O maior percentual foi observado na população com 15 anos ou mais de estudo $(89,8 \%)$. E, dos 85,6 milhões de usuários da Internet, 32,4\% (27,8 milhões) eram estudantes, enquanto $67,6 \%$ (57,8 milhões) eram não estudantes.

Ao analisar a rede de ensino frequentada, o IBGE observou que, dos 37,1 milhões de estudantes no País, $75,6 \%$ (28,0 milhões) eram da rede pública, e desses, $68,0 \%$ (19,1 milhões) utilizavam a Internet. Na rede privada, encontravam-se 9,0 milhões de estudantes, dentre os quais $96,3 \%$ (8,7 milhões) utilizavam a Internet.

$\mathrm{O}$ estudo faz menção à proporção de pessoas com acesso à Internet de acordo com a renda. Notou-se que conforme aumentava a classe de rendimento mensal domiciliar per capita maior era percentual de usuários da internet. Assim, 89,9\% foi observado na classe de mais de 10 salários mínimos, enquanto 23,9\% na classe sem rendimento a $1 / 4$ do salário mínimo.

Neste sentido, percebemos o quanto estas variáveis (como sexo, idade, escolaridade, frequência de rede de ensino e renda) são importantes e podem implicar no acesso às tecnologias e na inclusão digital. Por esta razão, vários governos estão a investir em programas de 
Inclusão Digital para proporcionar aos cidadãos empregabilidade, renda e acesso às tecnologias.

Entendemos que o processo de inclusão se realiza mediante três aspectos: 1) Econômicos, em que os indivíduos devem ter condições financeiras para acessar as tecnologias; 2) Cognitivos, pois as pessoas necessitam possuir uma visão crítica e capacidade independente de uso e apropriação dos novos meios digitais, isto é, aquilo que chamamos letramento ou literacia digital; e 3) Aspectos técnicos, dado que os indivíduos necessitam de conhecimentos operacionais sobre programas e para acessar à internet.

Partindo desse pressuposto, argumentamos como estas tecnologias podem ser usadas no ambiente escolar para incluir digitalmente aqueles adolescentes que encontram-se socialmente excluídos.

Após aplicação do questionário socioeconômico aos estudantes do Instituto Federal de Educação, Ciência e Tecnologia do Amazonas- Campus Manaus Zona Leste, no primeiro semestre do ano de 2016, recolheu-se os dados que demonstraram como resultado o perfil socioeconômico e o nível de conhecimento e acesso dos estudantes às tecnologias da informação e comunicação.

- Ao questionarmos sobre cor/raça dos estudantes, observamos que a maioria dos estudantes, $76 \%$, considera-se parda e a minoria, $2 \%$ se consideram amarela.

- Quanto à religião, tivemos um número aproximado entre católicos e evangélicos, enquanto $46 \%$ são evangélicos, $37 \%$ se dizem católicos, por outro lado, apenas um (01) estudante considerou-se umbanda ou do candomblé;

- Em relação ao estado civil dos estudantes, $89 \%$ são solteiros, e sobre filhos $82 \%$ afirmaram não ter filhos. Este resultado é justificado pela faixa-etária em que estão compreendidos a maioria dos estudantes, uma vez que são do ensino médio integrado, ou seja, ainda adolescentes (13 a 18 anos);

- Em seguida, questionamos se o estudante participa na vida econômica de sua família e 78\% (502) estudantes afirmou que não, pois são sustentados pela família ou por outras pessoas. Reforçando que este é um resultado já esperado, visto que a maioria dos estudantes são ainda adolescentes e estudam em tempo integral, conforme citado anteriormente;

- Fazendo uma análise socioeconômica dos participantes, percebemos que $33 \%$ possuem renda familiar de até um salário mínimo (880 reais) e dividem esta renda pelo número de pessoas da casa que, por sua vez, tem em média de três a cinco pessoas (63\%);

- Quanto ao principal mantenedor do lar notou-se que embora ainda estejamos em uma sociedade patriarcal, onde o homem surge como autoridade maior na organização social, o cenário tem se configurado de maneira diferente. Os resultados indicam existir uma igualdade no papel de provedor do lar entre pai e mãe, ambos com a mesma taxa de respostas (33\%);

- Notou-se que $68 \%$ dos estudantes residem em casa própria e apenas $1 \%$ é herdada;

- Sobre a percepção dos estudantes acerca dos recursos tecnológicos, $50 \%$ dos estudantes informaram que tiveram primeiro acesso ao computador entre 10 e 14 anos de idade;

- Sobre a relação do estudante com o computador. $53 \%$ consideraram "ter alguma noção" e apenas 5\% acreditam "ter muita experiência", ou seja, domínio do uso do microcomputador;

- A maioria dos estudantes $(81 \%)$ tem algum tipo de acesso à internet. Esse acesso acontece na própria casa $(51 \%)$ e via celular (28\%);

- Sobre os principais motivos do uso da internet, $52 \%$ informaram que utilizam na busca de informações e notícias de seu interesse, seguido de $30 \%$ que utilizam na pesquisa para atividades escolares;

Quanto aos recursos tecnológicos que estes estudantes possuem, 54\% respondeu que possuem somente celular, seguido de $18 \%$ que possuem notebook e celular e apenas $1 \%$ possuem todos os recursos mencionados (computador, notebook, tablet e celular);

- Para a maioria dos estudantes o uso de recursos tecnológicos é muito importante (68\%). E 85\% gostariam que fossem utilizados recursos tecnológicos na sala de aula;

- Buscou-se também saber se os estudantes possuem celular, tendo os mesmos informado, em sua maioria (87\%) que sim, e que usam o celular todos os dias (54\%), em média de 1 a 2 horas por dia (45\%).

- Questionados ainda sobre o tipo de celular e sua tecnologia, $63 \%$ informaram possuir um smartphone e $78 \%$ utilizam a tecnologia Android. Desvelou-se também que $66 \%$ costumam utilizar e baixar aplicativos móveis para seus celulares.

Conforme a ONU, na resolução A/HRC/32/L.20 recentemente aprovada, em 27 de junho de 2016, o indivíduo tem o direito à inclusão digital, e o incluído tem o dever de reconhecer que esse direito deve ser estendido a todos. Dessa forma, inclusão digital é um processo que deve levar o indivíduo à aprendizagem no uso das TIC e ao acesso à informação disponível nas redes, especialmente aquela que fará diferença para a sua vida e para a comunidade na qual está inserido.

\section{Considerações Finais}

Corroboramos com Sposati (2006) quando supõe que há na sociedade a busca pelo que é bom e desejável para todos, justificando a presença da luta pela igualdade ou, pelo menos, um patamar básico de igualdade. Também temos presente que fazemos parte de uma sociedade desigual, marcada por profundas assimetrias. Frente a essa desigualdade surge a necessidade de nos incluirmos socialmente.

A inclusão digital através da escola possui o papel de resgatar os excluídos digitais, de forma a incluí-los no contexto da sociedade movida pelos processos de criação, produção e sublimação da informação em conhecimento. Significa o empoderamento dos sujeitos para uso das tecnologias da informação e comunicação. Tendo como prioridade a efetivação de políticas públicas que visem o seu crescimento educacional, pessoal e profissional.

Não podemos deixar de ter em conta o pensamento de Paulo Freire (1984, p.6) "Para mim os computadores 
são um negócio extraordinário. O problema é saber a serviço de quem eles entram na escola". Devemos, assim, pôr em debate de que forma a escola pode utilizar de forma proveitosa e eficiente essas tecnologias para que tenham um efeito positivo no exercício de uma cidadania plena.

Vale ressaltar que é na escola que inicia esse processo de ensino-aprendizagem, por isso, este ambiente não pode ficar alheio a essas mudanças. A evolução deve fazer parte do ambiente escolar, fazendo necessário o uso das TIC dentro das escolas como promoção de uma educação inclusiva e digital.

A integração das TIC na escola implica diversos desafios, entre estes: a necessidade de mudanças nos currículos; a capacitação dos professores para uso das tecnologias; vencer as resistências dos profissionais e instituições conservadoras; aprender a valorizar a informação valiosa de forma a descartar a presença de informações fúteis e inverídicas na rede, entre outros desafios.

Cabe à escola propor mecanismos para vencer tais desafios. Entendemos que se deve estimular o conhecimento renovado e crítico para diminuição das desigualdades sociais, contribuindo assim com a democratização da escola. Para Tedesco (2002), a educação tem como desafio do futuro, modificar seu papel diante da mobilidade social. Por um lado, será a variável mais importante que permitirá entrar ou ficar fora do círculo no qual se definem e realizam as atividades socialmente mais significativas e, por outro, será necessário educar-se ao longo de toda a vida para poder adaptar-se aos requerimentos do desempenho social e produtivo. Assim, o papel da escola deve ser definido pela sua capacidade de preparar para o uso consciente, crítico, ativo dos aparatos que acumulam a informação e o conhecimento (TEDESCO, 2002, p27).

Diante desta pesquisa, primeiro momento exploratório sobre a inclusão social e digital que faz parte de um projeto mais amplo (dissertação de mestrado) foi possível refletir acerca do mundo em que vivemos e das tamanhas desigualdades existentes em um único Campus. Percebeu-se que as condições de localidade, de sobrevivência e renda (emprego, alimentação, moradia, etc.), familiar, educação dos pais e o próprio ambiente em que vivem e se relacionam podem interferir no acesso às tecnologias. Diante de tantos desafios, a escola pode e deve assumir-se como fator primordial para transformação e inclusão social e digital. Esperamos trazer, em outra oportunidade, resultados mais sólidos desta pesquisa sobre esta temática.

\section{Referências}

Bauman, Z. (2001). Modernidade líquida. Rio de Janeiro: Jorge Zahar Editor.

Castells, M. (2002). A Sociedade em Rede. A Era da Informação, Sociedade e Cultura - Volume I. Lisboa: Fundação Calouste Gulbenkian.

IBGE (2015). Acesso à internet e à televisão e posse de telefone móvel celular para uso pessoal : 2013 . Rio de Janeiro.
IBGE (2016). Demográfico. Disponível em: http://www.ibge.com.br. Acesso em 25 de junho de 2017.

IWS (2016). Internet world stats: Usage and population statistics. Internet world stats. Disponível em http://www.internetworldstats.com.

FGV (2003). O Mapa da Exclusão Digital. Revista Conjuntura Econômica. Rio de Janeiro.

Filho, A. (2003). Os três pilares da inclusão digital. Revista Espaço Acadêmico, 3(24), 5.

Fink, A.; Koawxoff, J. (1998) How to conduct surveys a step-by-step guide. California: Thousand Oaks, Sage Publications.

Forza, C. (2002) Survey research in operations management: a process-based perspective. International Journal of Operations \& Production Management, v. 22, n. 2, p. 152-194.

Freitas, H., Oliveira, M., Saccol, A. Z., \& Moscarola, J. (2000). O método de pesquisa survey. Revista de administração, 35(3), pp.105-112.

Freire, P. (1984). A máquina está a serviço de quem?. Obra de Paulo Freire; Série Artigos.

ONU (2016). The promotion, protection and enjoyment of human rights on the Internet. Resolução A/HRC/32/L.20. Disponível em http://ap.ohchr.org/documents/dpage_e.aspx?si=A/HR C/32/L.20.

Sarmento, M. J. (2002). Infância, exclusão social e educação como utopia realizável. Educação $e$ sociedade, 23(78), 265-283.

Silva, B. D., \& Pereira, M. (2011). O papel da escola no combate à divisão digital. In: XI Congresso Luso Afro Brasileiro de Ciências Sociais: diversidades e (des) igualdades. Universidade Federal da Bahia.

Sposati, A. (2006). A fluidez da inclusão/exclusão social. Ciência e Cultura, 58(4), 4-5.

Tedesco, J. (2002). Os fenômenos de segregação e exclusão social na sociedade do conhecimento. Cadernos de Pesquisa, 117, 13-28.

Tosoni, A., Luchetta, L.M., e Dabul, R.M. (2011). As TICs no contexto da Inclusão Digital. Disponível em: http://assespro.org.br/na-midia/artigos/2011-07-04-astics-no-contexto-da-inclus-227-o-digital/. Acesso em: 10 de junho de 2017.

UNESCO/Brasil (2010). Educação, um tesouro a descubrir. Relatório para a UNESCO publicado em 1998 da Comissão Internacional sobre a Educação para o século XXI. Brasília: Faber-Castell (comissão cordenada por Jacques Delors). 